Check for updates

Cite this: J. Mater. Chem. A, 2018, 6, 23569

Received 22nd September 2018 Accepted 19th October 2018

DOI: $10.1039 / c 8 t a 09227 c$

rsc.li/materials-a

\section{Compaction of a zirconium metal-organic framework (UiO-66) for high density hydrogen storage applications $\dagger$}

\author{
Sonwabo E. Bambalaza, ${ }^{\text {ab }}$ Henrietta W. Langmi, (D) *a Robert Mokaya, (D) ${ }^{c}$ \\ Nicholas M. Musyoka, ${ }^{\text {a }}$ Jianwei Ren ${ }^{\text {ad }}$ and Lindiwe E. Khotseng ${ }^{\text {b }}$
}

We report a rare case whereby a metal-organic framework (MOF), namely UiO-66, is compacted at high pressure ( $700 \mathrm{MPa}$ or $100000 \mathrm{psi}$ ) resulting in densification and improved total volumetric hydrogen storage capacity, but crucially, without compromising the total gravimetric uptake attained in the powdered form of the MOF. The applied compaction pressure is also unprecedented for MOFs as most studies have shown the MOF structure to collapse when compacted at very high pressure. The UiO-66 prepared in this study retained $\sim 98 \%$ of the original surface area and microporosity after compaction at $\sim 700 \mathrm{MPa}$, and the densified pellets achieved a total $\mathrm{H}_{2}$ uptake of $5.1 \mathrm{wt} \%$ at 100 bar and $77 \mathrm{~K}$ compared to $5.0 \mathrm{wt} \%$ for the UiO-66 powder. Depending on the method used to compute the volumetric uptake, the densified $\mathrm{UiO}-66$ attained unprecedented volumetric capacity at $77 \mathrm{~K}$ and 100 bar of up to $74 \mathrm{~g} \mathrm{~L}^{-1}$ (13 $\mathrm{g} \mathrm{L}^{-1}$ at $298 \mathrm{~K}$ ) compared to $29 \mathrm{~g} \mathrm{~L}^{-1}$ for the powder $\left(6 \mathrm{~g} \mathrm{~L}^{-1}\right.$ at $\left.298 \mathrm{~K}\right)$ using a conventional method that takes into account the packing density of the adsorbents, or $43 \mathrm{~g} \mathrm{~L}^{-1}$ (compared to $35 \mathrm{~g} \mathrm{~L}^{-1}$ for the powder at $77 \mathrm{~K}$ and $100 \mathrm{bar}$ ) based on a method that uses both the single crystal and skeletal densities of MOFs. However, regardless of the difference in the calculated values according to the two methods, the concept of $\mathrm{UiO}-66$ compaction for improving volumetric capacity without compromising gravimetric uptake is clearly proven in this study and shows promise for the achievement of hydrogen storage targets for a single material as set by the United States Department of Energy (DOE).

\section{Introduction}

The use of metal-organic frameworks (MOFs) in cryogenic hydrogen $\left(\mathrm{H}_{2}\right)$ storage applications has shown great promise due to the high surface areas and large micropore volumes exhibited by MOFs such as MOF-5 and MOF-177, among others. ${ }^{1}$ The highest measured total gravimetric uptake of $16.4 \mathrm{wt} \% \mathrm{H}_{2}$ was reported for the copper-based paddlewheel MOF NU-100 at $77 \mathrm{~K}$ at a moderate pressure of 70 bar. $^{2}$ Coupled to the high $\mathrm{H}_{2}$ adsorption capacities that can be displayed, the

${ }^{a}$ HySA Infrastructure Centre of Competence, Energy Centre, Council for Scientific and Industrial Research (CSIR), PO Box 395, Pretoria 0001, South Africa. E-mail: hlangmi@csir.co.za

${ }^{b}$ Faculty of Natural Science, University of the Western Cape, Bellville, Cape Town 7535 , South Africa

${ }^{c}$ School of Chemistry, University of Nottingham, University Park, Nottingham, NG7 $2 R D, U K$

${ }^{d}$ Mechanical Engineering Science Department, University of Johannesburg, Johannesburg, South Africa

$\dagger$ Electronic supplementary information (ESI) available: Six additional figures (consisting of SEM images, TGA analysis, comparative nitrogen isotherms and pore size distribution curves, and adsorbed $\mathrm{H}_{2}$ volume fractions), and two tables (consisting of comparative textural properties, packing density, and $\mathrm{H}_{2}$ uptake). See DOI: 10.1039/c8ta09227c physisorption-based adsorption mechanism also allows for fast kinetics for the uptake and release (desorption) of $\mathrm{H}_{2}$ molecules with minimal energy inputs, making MOFs good candidates for use in on-board $\mathrm{H}_{2}$ storage systems in fuel cell vehicles. ${ }^{3}$ Additionally, more recently there have been attempts to make the synthesis of MOFs relatively simple and inexpensive, and best practices involved in their synthesis, activation and characterisation have been outlined. ${ }^{4}$ Synthesis procedures may include microwave-assisted methods, ${ }^{5,6}$ solvent-free routes, ${ }^{7}$ and the use of MOF precursors derived from waste materials, e.g. use of terephthalic acid $\left(\mathrm{H}_{2} \mathrm{BDC}\right)$ derived from waste polyethylene terephthalate (PET) to synthesise Zr-based MOF (UiO-66) and Cr-MOFs (MIL-101 and MIL-53). ${ }^{8-10}$ The combination of favourable surface areas and micropore volumes for physisorption-based $\mathrm{H}_{2}$ storage, and potential green synthesis methods renders MOFs as being of high interest and promising for industrial applications.

The potential use of MOFs for material-based on-board hydrogen storage systems requires the selection of candidate MOFs that meet certain universally accepted targets. An example of such targets for 2020, as offered by the United States Department of Energy (DOE), require that the system has a gravimetric uptake of $4.5 \mathrm{wt} \% \mathrm{H}_{2}$ and a volumetric capacity of $30 \mathrm{~g} \mathrm{~L}^{-1} \mathrm{H}_{2} \cdot{ }^{11}$ While some MOFs have been reported to attain 
total gravimetric $\mathrm{H}_{2}$ uptake exceeding $10 \mathrm{wt} \%$, their respective volumetric $\mathrm{H}_{2}$ capacities seldom reach $30 \mathrm{~g} \mathrm{~L}^{-1}$. Indeed, many different types of MOFs have been assessed in efforts to reach these targets such as in the study by Goldsmith et al. ${ }^{\mathbf{1 2}}$ who explored the relationship between total gravimetric uptake and total volumetric $\mathrm{H}_{2}$ capacity for a large number of MOFs. It was found that most MOFs have relatively low total volumetric densities and only a few were within the 2017 DOE target at the time $\left(5.5 \mathrm{wt} \% ; 40 \mathrm{~g} \mathrm{~L}^{-1}\right)$ for a single storage material. The results indicated that a maximum volumetric $\mathrm{H}_{2}$ capacity of about $55 \mathrm{~g} \mathrm{~L}^{-1}$ was reachable, but that any further changes in materials properties to increase the total gravimetric $\mathrm{H}_{2}$ uptake resulted in a reduction in the total volumetric $\mathrm{H}_{2}$ capacity. This means that the surface area of the best performing MOFs should be limited to those that do not compromise the total volumetric $\mathrm{H}_{2}$ storage capacity of the MOF. Therefore, for $\mathrm{H}_{2}$ storage applications using MOFs, the focus needs to shift towards the direction where both the total volumetric $\mathrm{H}_{2}$ storage capacities and surface areas are simultaneously improved while maintaining the crystal structure of the MOF material.

As an alternative, the compaction of powdered samples into shaped bodies such as monoliths has been implemented to improve the total volumetric $\mathrm{H}_{2}$ capacity of MOFs. However, in most cases this improvement in volumetric capacity is always accompanied by a reduction in gravimetric uptake. ${ }^{13-16}$ Most of the previous studies on gas adsorption showed that the total volumetric $\mathrm{H}_{2}$ capacity of adsorbed gas is related to the density of the adsorbent and that by using shaping strategies such as compaction, the relatively low densities of MOFs can be increased in order to improve their total volumetric $\mathrm{H}_{2}$ storage capacity. ${ }^{13-15}$ Indeed, a study by Ardelean et al. ${ }^{16}$ reported the compaction of MIL-101 (Cr) powder to achieve envelope densities close to the crystal density of MIL-101 (Cr) and the resultant "monoliths" were shown to have an impressive total volumetric $\mathrm{H}_{2}$ capacity of $40 \mathrm{~g} \mathrm{~L}^{-1}$.

The challenge, however, is that the application of external pressure onto nanostructured porous materials has been shown to typically result in the reduction of surface area and may also induce the amorphisation of MOF crystals. ${ }^{17-19}$ Another response of porous materials to external applied pressure includes anisotropic changes in crystal topology, such as seen in the MIL family of MOFs (e.g. MIL-53 and MIL-101), ${ }^{20}$ which may result in widening of pores. These structural changes can have a direct impact to gas adsorption and it is generally observed in MOFs that upon compaction, the surface area reduces and results in a diminished total gravimetric $\mathrm{H}_{2}$ uptake. ${ }^{17,18,21-23}$ In order to counteract this inverse relationship between gravimetric $\mathrm{H}_{2}$ uptake and compaction (i.e. densification), the use of highly robust MOFs which show high resistance to applied pressure is desirable for MOF-based materials that retain their initial surface area and micropore volumes upon compaction at high pressure.

The textural properties of MOFs may also be modified by applying simple adjustments to the MOF synthesis conditions. ${ }^{24-28}$ One of the extensively investigated methods is the synthesis of MOFs with defects or missing organic linkers in their crystal lattice, which results in the presence of open metal sites within the MOF crystal structure..$^{29-33}$ At the open transition metal (TM) centres there exists an opportunity for enhanced TM to gas interactions that may improve gas uptake as described in previous studies. ${ }^{34-36}$ The compaction of MOFs has been shown to lead to increased volumetric $\mathrm{H}_{2}$ capacities and in this study we aim to investigate the effects of compaction at significantly higher pressures ( 700 MPa or $100000 \mathrm{psi})$ than previously reported for UiO-66, ${ }^{17}$ and possibly improve the volumetric $\mathrm{H}_{2}$ capacity for UiO-66 towards the DOE target of $30 \mathrm{~g} \mathrm{~L}^{-1}$.

\section{Experimental}

\subsection{Reagents and chemicals}

Zirconium tetrachloride $\left(\mathrm{ZrCl}_{4}\right.$, Sigma Aldrich, 99.5\%), 1,4benzenedicarboxylic acid (BDC, Sigma Aldrich, 98\%), $N, N$ dimethylformamide (DMF, Sigma Aldrich, 99.8\%), formic acid ( $\mathrm{HCOOH}$, Sigma Aldrich, 95\%) and dried acetone (Sigma Aldrich, 99.8\%) were purchased and used without further purification.

\subsection{Preparation of UiO-66}

UiO-66 crystals were synthesised, with minor modifications, using a previously reported method. ${ }^{27}$ Typically, to a $500 \mathrm{~mL}$ round-bottom flask, a 1 : 1 molar ratio of $\mathrm{ZrCl}_{4}$ : $\mathrm{BDC}$ was dissolved ultrasonically in $300 \mathrm{~mL}$ DMF for $1 \mathrm{~h}$. To the mixture a 100 molar equivalent of formic acid was then added as a modulator and the flask capped with a thick-walled balloon. The reaction mixture was heated and maintained at $120^{\circ} \mathrm{C}$ for $5 \mathrm{~h}$ and thereafter cooled to room temperature. The resulting white product was collected by centrifugation and washed in dried acetone and after re-collection, the solid product was dried under vacuum at room temperature.

\subsection{Compaction of UiO-66}

In order to select the optimum process parameters for compaction, a screening experiment was conducted whereby $\sim 400 \mathrm{mg}$ UiO-66 powder was compacted in a $13 \mathrm{~mm}$ diameter die $\left(\right.$ area $=113 \mathrm{~mm}^{2}$ ) at 2, 4, 6, 8, and 9 metric tonnes (i.e. $\sim 150$, 290, 440, 590, and $665 \mathrm{MPa}$ applied pressure) in a Specac Manual Hydraulic Press for 15 minutes. The highest applied compaction pressure where the crystallinity of UiO-66 was still maintained giving the highest packing density for UiO-66 was chosen for $\mathrm{H}_{2}$ uptake measurements up to a hydrogen pressure of 100 bar.

\subsection{Characterisation}

Powder X-ray diffraction (PXRD) patterns of powdered and compacted UiO-66 were collected within the $2 \theta$ range of $3-90^{\circ}$ using a Rigaku Ultima IV X-ray diffractometer with CBO technology using Ni-filtered $\mathrm{Cu}-\mathrm{K} \alpha$ radiation of $0.154 \mathrm{~nm}(40 \mathrm{kV}$, $30 \mathrm{~mA}$ ) at a scanning speed of $2^{\circ} \mathrm{s}^{-1}$. The PXRD pattern of the compacted UiO-66 was done on a $1 \mathrm{~mm} \times 20 \mathrm{~mm}$ pellet and mounted onto the PXRD sample holder by thinning the edges so that it fits into the well of the sample holder. The surface morphology was analysed using an Auriga cobra Focused-Ion Beam Scanning Electron Microscope (FIB-SEM) where each 
sample was mounted on a carbon tape and coated with carbon (where necessary) prior to each analysis. Nitrogen sorption and desorption isotherms were obtained on a Micromeritics 3 Flex sorptometer at $77 \mathrm{~K}$ and relative pressure $\left(p / p_{\mathrm{o}}\right)$ of up to 1 . Pore size distribution (PSD) curves were obtained using the NonLocal Density Functional Theory (NLDFT) model. Ultra-high purity grade (99.999\%) nitrogen gas was used and each sample was degassed on a Micromeritics Smart VacPrep under vacuum (down to $10^{-7}$ bar) with heating up to $80{ }^{\circ} \mathrm{C}$ for $32 \mathrm{~h}$ prior to each sorption isotherm measurement. The thermal stabilities of pristine and composite materials were measured with a thermogravimetric analyzer (TGA) (Mettler, Toledo, TGA/ SDTA 851e) on degassed samples. For each run, $\sim 10 \mathrm{mg}$ sample was heated to $1000{ }^{\circ} \mathrm{C}$ at a ramp rate of $10{ }^{\circ} \mathrm{C} \min ^{-1}$ under $100 \mathrm{~mL} \min ^{-1}$ airflow. Excess hydrogen uptake measurements were obtained from $0-100$ bar at $77 \mathrm{~K}$ or room temperature using 6.0 grade $\mathrm{H}_{2} \quad(99.9999 \%)$, additionally purified by a molecular sieve filter, on a Hiden Isochema XEMIS intelligent gravimetric analyser. The measured excess $\mathrm{H}_{2}$ uptake was obtained under non-equilibrium (dynamic) conditions as time intervals at each $\mathrm{H}_{2}$ pressure were manually inserted prior to the analysis. The measurements were also corrected for buoyancy effects, where the skeletal density of each MOF sample was determined by Helium pycnometry. The total $\mathrm{H}_{2}$ uptake was calculated based on the Langmuir surface coverage of adsorbed $\mathrm{H}_{2}$ at specified pressures as shown in eqn (1).

$$
\theta_{\mathrm{T}}=\theta_{\mathrm{Exc}}+\frac{d_{\mathrm{H}_{2}} \times V_{\mathrm{T}}}{\left(1+d_{\mathrm{H}_{2}} \times V_{\mathrm{T}}\right)} \times 100 \%
$$

$\theta_{\mathrm{T}}=$ total hydrogen uptake (wt $\left.\%\right), \theta_{\mathrm{Exc}}=$ excess hydrogen uptake (wt\%), $d_{\mathrm{H}_{2}}=$ density $\left(\mathrm{g} \mathrm{cm}^{-3}\right)$ of compressed $\mathrm{H}_{2}$ gas at the relevant temperature and pressure. The $\mathrm{H}_{2}$ densities at $77 \mathrm{~K}$ in the 0-100 bar range were obtained from the National Institute of Standards and Technology (NIST) website. ${ }^{54} V_{\mathrm{T}}=$ pore volume obtained from $\mathrm{N}_{2}$ isotherm data.

The total volumetric $\mathrm{H}_{2}$ capacity was calculated from the gravimetric data using two approaches. The most commonly reported approach uses the packing density of the MOF material to calculate the total volumetric capacity as shown in eqn (2) and (3). The second approach comes from a recent study by Ahmed et al. ${ }^{37}$ who highlighted some recommendations made by Parilla et al. ${ }^{38}$ where the total volumetric $\mathrm{H}_{2}$ capacity was calculated from gravimetric data (excess $\mathrm{H}_{2}$ uptake in wt\%) using both the single crystal and skeletal densities of MOFs according to eqn (4).

$$
\begin{gathered}
v \theta_{\mathrm{Exc}}=\theta_{\mathrm{Exc}} \times d_{\mathrm{MOF}} \\
v \theta_{\mathrm{T}}=\theta_{\mathrm{T}} \times d_{\mathrm{MOF}}
\end{gathered}
$$

$v \theta_{\text {Exc }}=$ excess volumetric uptake $\left(\mathrm{g} \mathrm{L}^{-1}\right), d_{\mathrm{MOF}}=$ packing density of MOF material $\left(\mathrm{g} \mathrm{L}^{-1}\right)$.

$$
n_{\mathrm{v}}=p_{\text {crys }} n_{\text {ex }}+p_{\text {gas }}\left(1-\frac{p_{\text {crys }}}{p_{\text {sk }}}\right)
$$

$n_{\mathrm{v}}=$ total volumetric $\mathrm{H}_{2}$ capacity $\left(\mathrm{g} \mathrm{L}^{-1}\right), p_{\text {crys }}=$ single crystal density for UiO-66 $\left(1.24 \mathrm{~g} \mathrm{~cm}^{-3}\right.$ as reported by Goldsmith et al. $\left.{ }^{12}\right) \cdot n_{\mathrm{ex}}=$ measured excess $\mathrm{H}_{2}$ adsorption $\left(\mathrm{g} \mathrm{kg}^{-1}\right) \cdot p_{\text {gas }}=$ bulk density of $\mathrm{H}_{2}$ gas at a given pressure $\left(\mathrm{g} \mathrm{dm}^{-3}\right)$ obtainable from the NIST website. ${ }^{54} p_{\mathrm{sk}}=$ skeletal density of the MOF $\left(\mathrm{g} \mathrm{cm}^{-3}\right)$.

\section{Results \& discussion}

The XRD pattern (Fig. 1a), and SEM image (Fig. S1, $\operatorname{ESI} \dagger$ ), respectively showed typical UiO-66 $2 \theta$ peak positions $(\sim 8,9$, and $25^{\circ}$ ) and octahedral crystal shapes as reported in previous studies. ${ }^{39-41}$ As can be seen in Fig. 1a there was very little difference in XRD patterns of compacted UiO-66 with increasing applied compaction pressure. The peak intensities, however, were found to slightly decrease and some evidence of peak broadening was also observed at high compaction pressure which may be caused by the onset of an amorphisation process (Fig. 1b). Nevertheless, the XRD patterns for UiO-66 compacted up to $665 \mathrm{MPa}$ generally show the UiO-66 crystal structure was essentially retained upon compaction. The presence of the symmetry forbidden $\left(\begin{array}{lll}1 & 1 & 0\end{array}\right)$ reflection at the $2 \theta$ value of $\sim 6^{\circ}$ was the first indication for the synthesis UiO-66 crystals with defects, i.e., crystals consisting of missing benzene dicarboxylate (BDC) organic linkers and hence the existence of open $\mathrm{Zr}$ centres. ${ }^{31}$ As further indication for defect UiO-66, TGA results (Fig. S2, ESI $\dagger$ ) show that the complete structural collapse of the UiO-66 framework at $\sim 500{ }^{\circ} \mathrm{C}$ yielded a final residue of about $37 \mathrm{wt} \%$, the composition of which is the non-porous solid $\mathrm{ZrO}_{2}{ }^{42}$ Previous studies by Valenzano et al. ${ }^{30}$ and Chavan et al. ${ }^{43}$ have demonstrated the use of TGA data to deduce the presence/ absence of BDC linkers in UiO-66. Having found their as-prepared UiO-66 crystal structure to be made up of $\mathrm{Zr}_{6} \mathrm{O}_{4}$ $(\mathrm{OH})_{2}(\mathrm{BDC})_{12}$ clusters, which undergo desolvation and dehydroxylation up to $300{ }^{\circ} \mathrm{C}$ to form $\mathrm{Zr}_{6} \mathrm{O}_{6}(\mathrm{BDC})_{12}$ clusters, they showed that the final $\mathrm{ZrO}_{2}$ residue after framework collapse should yield no less than $45 \mathrm{wt} \%$ for perfect UiO-66 crystals with no defects. Final $\mathrm{ZrO}_{2}$ residues below $45 \mathrm{wt} \%$ would constitute one missing BDC linker per cluster, assuming an evenly distributed presence of defects. The TGA results obtained in this study also support a multi-step decomposition of UiO-66 between $90-300{ }^{\circ} \mathrm{C}$ before framework collapse at $\sim 500{ }^{\circ} \mathrm{C}$, and these early mass loss events might involve the removal of DMF and $\mathrm{H}_{2} \mathrm{O}$ molecules by desolvation and dehydroxylation, respectively. Regarding thermal stability, we also found that the temperature at which thermal treatment (i.e., evacuation) was carried out prior to porosity determination had an influence on the BET surface area and porosity of UiO-66. The as-prepared UiO-66 samples heat treated under vacuum at $80{ }^{\circ} \mathrm{C}$ for $32 \mathrm{~h}$ showed higher BET surface area and pore volume than samples heat treated at $200{ }^{\circ} \mathrm{C}$ for $8 \mathrm{~h}$ under vacuum (Fig. S3, ESI $\dagger$ ). This result may suggest the existence of UiO-66 polymorphic forms (hydroxylated and dehydroxylated forms) with slightly different gas adsorption properties in a manner similar to the findings reported by Chavan et al. ${ }^{43}$ and others. ${ }^{30,32}$

In Fig. 2a the $\mathrm{N}_{2}$ adsorption isotherms for both powder and compacted UiO-66 show type I adsorption and in Table 1 it can be seen that the compacted UiO-66 showed a less than $2 \%$ decrease in BET surface area $\left(1707 \mathrm{~m}^{2} \mathrm{~g}^{-1}\right)$ compared to UiO-66 

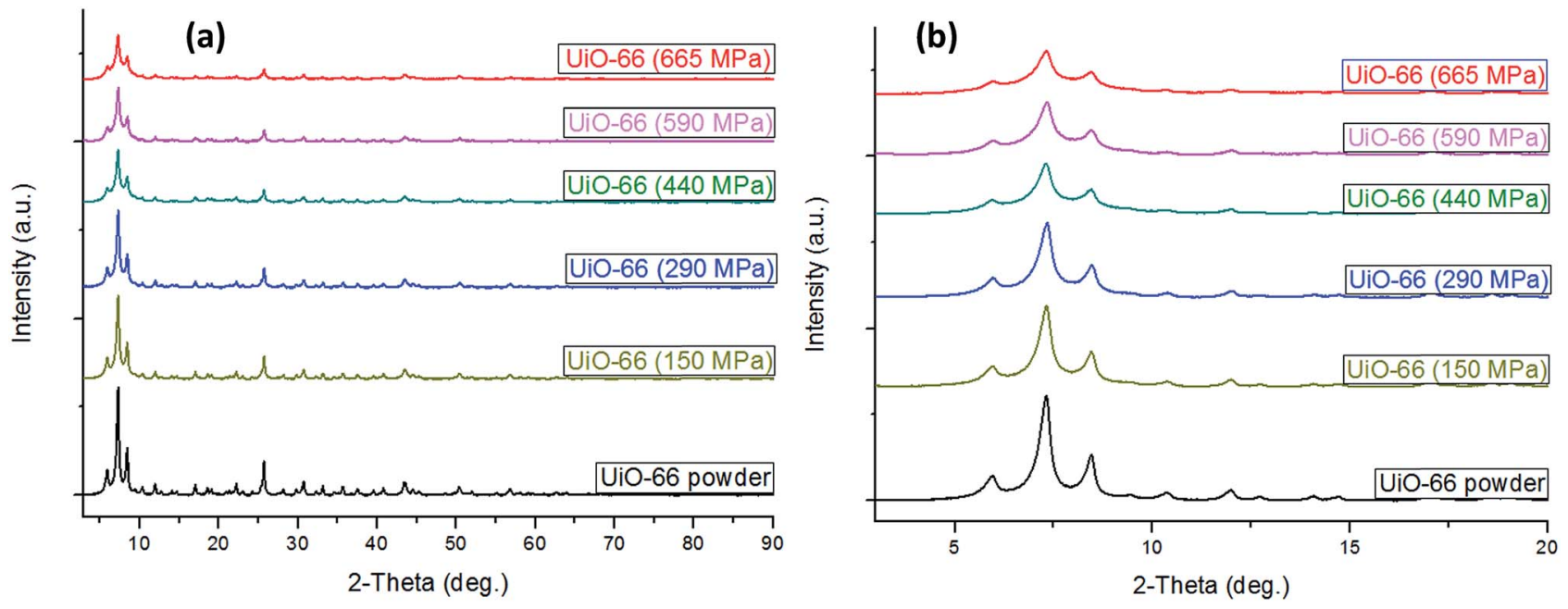

Fig. 1 PXRD patterns of UiO-66 at increasing compaction pressure (0-665 MPa): (a) full patterns showing all peak positions for UiO-66, (b) section of the patterns from $2 \theta=3-20^{\circ}$ showing no changes to peak positions with increasing applied pressure.

powder $\left(1737 \mathrm{~m}^{2} \mathrm{~g}^{-1}\right)$, and $\sim 5 \%$ reduction in micropore surface area and micropore volume. Such a result is unusual for MOFs, as given the nature of their highly porous crystal structure, it can be expected that they show high compressibility, and negative response to applied pressure. Wu et al. ${ }^{44}$ have reported that the minimum shear modulus for UiO-66 is $c a$. 13.7 GPa due to the strong $\mathrm{Zr}-\mathrm{O}$ bonding in its crystal lattice, and is much higher than the value for most MOFs such as ZIF-8 (ca. 2.7) and MIL-53 (Ga) (ca. 0.16 GPa). ${ }^{45}$ Therefore, due to the little changes in crystal structure at $\sim 665 \mathrm{MPa}$, it can be expected that UiO-66 crystals would retain most of their textural properties at applied compaction pressures below the minimum shear modulus, as shown in this study. The total pore volume (Table 1), on the other hand, was found to differ more significantly with UiO-66 powder having $0.96 \mathrm{~cm}^{3} \mathrm{~g}^{-1}$ whereas the UiO-66 pellet was $0.81 \mathrm{~cm}^{3} \mathrm{~g}^{-1}$, a $16 \%$ reduction in total pore volume. This can be attributed to the significant reduction in macropores that are due to interparticle voids that are removed upon compaction as a result of the close packing of the particles (Fig. S4, ESI $\dagger$ ).

The pore size distribution curves shown in Fig. $2 \mathrm{~b}$ are consistent with reported literature with pores of size $\sim 6,8$ and $11 \AA$, which correspond to the free diameters in tetrahedral cages, triangular windows and octahedral cages of UiO-66, respectively. ${ }^{46,47}$ There was also evidence of a broadened pore size distribution towards higher values, with peaks at $\sim 14 \AA$ up to $\sim 18 \AA$ which was an additional sign of UiO- 66 crystals with defects and possibly open $\mathrm{Zr}$ metal sites. The observation of retention of UiO-66 crystal structure after compaction up to $665 \mathrm{MPa}$ as evident from the X-ray diffraction patterns in Fig. 1 was also translated in the textural properties of powdered and compacted UiO-66 forms (Fig. 2). A noticeable feature of the UiO-66 prepared in this study is that the surface area and pore volumes obtained are amongst the highest values reported for UiO-66 prepared using organic acid modulators. ${ }^{31,48}$ Shearer
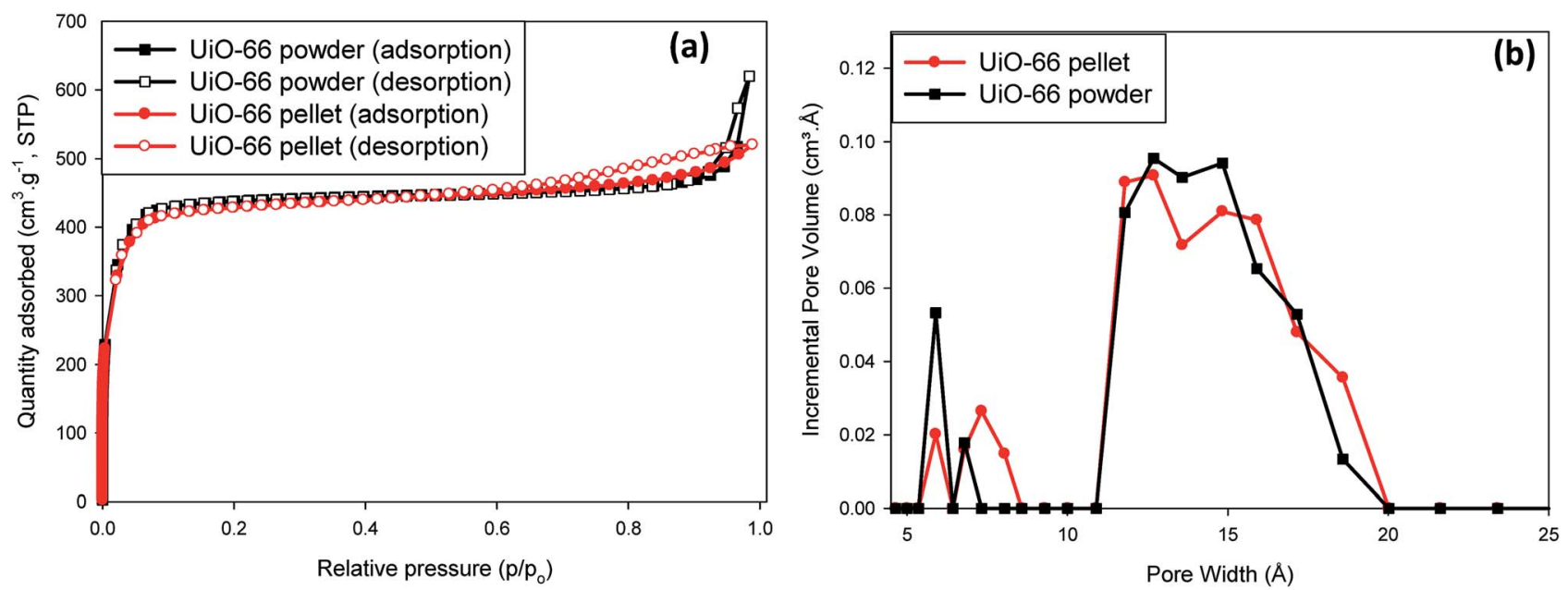

Fig. 2 Textural properties for UiO-66 before and after compaction at $665 \mathrm{MPa}$ : (a) $\mathrm{N}_{2}$ isotherms at $77 \mathrm{~K}$; (b) pore size distribution in the micropore region (PSD < $20 \AA$ ). 
Table 1 Textural properties, packing density, and $\mathrm{H}_{2}$ uptake (77 K and 100 bar or $298 \mathrm{~K}$ for values in parenthesis) measured for powder and compacted UiO-66

\begin{tabular}{|c|c|c|c|c|c|c|c|c|c|}
\hline \multirow[b]{2}{*}{ Sample } & \multirow[b]{2}{*}{$\begin{array}{l}\text { Surface area } \\
\left(\mathrm{m}^{2} \mathrm{~g}^{-1}\right)\end{array}$} & \multirow[b]{2}{*}{$\begin{array}{l}\text { Pore volume } \\
\left(\mathrm{cm}^{3} \mathrm{~g}^{-1}\right)\end{array}$} & \multirow[b]{2}{*}{$\begin{array}{l}\text { Packing density } \\
\left(\mathrm{g} \mathrm{cm}^{-3}\right)\end{array}$} & \multirow[b]{2}{*}{$\begin{array}{l}\text { Skeletal density } \\
\left(\mathrm{g} \mathrm{cm}^{-3}\right)\end{array}$} & \multicolumn{2}{|c|}{$\begin{array}{l}\text { Gravimetric } \mathrm{H}_{2} \\
\text { uptake (wt } \%)\end{array}$} & \multicolumn{2}{|c|}{$\begin{array}{l}\text { Volumetric } \mathrm{H}_{2} \\
\text { capacity }\left(\mathrm{g} \mathrm{L}^{-1}\right)\end{array}$} & \multirow[b]{2}{*}{ Totaf } \\
\hline & & & & & Excess & Total & Excess $^{d}$ & Total $^{e}$ & \\
\hline UiO-66 powder & 1737 (1559, 90\%) & $0.96(0.60,63 \%)$ & $0.57^{c}$ & 1.65 & $2.1(0.4)$ & $5.0(1.1)$ & $12(2)$ & $29(6)$ & $35(7)$ \\
\hline UiO-66 pellet & $1707(1484,87 \%)$ & $0.81(0.57,70 \%)$ & 1.45 & 1.78 & $2.7(0.3)$ & $5.1(0.9)$ & $39(4)$ & $74(13)$ & $43(6)$ \\
\hline
\end{tabular}

${ }^{a}$ Values in parenthesis are micropore surface area and percentage micropore surface area of the total surface area. ${ }^{b}$ Values in parenthesis are micropore volume and percentage micropore of the total pore volume. ${ }^{c}$ Tapped density of UiO-66 powder. ${ }^{d}$ Excess volumetric capacity calculated from the packing density as per eqn (2). ${ }^{e}$ Total volumetric capacity calculated from the packing density as per eqn (3). ${ }^{f}$ Total volumetric $\mathrm{H}_{2}$ capacity calculated using the single crystal $\left(1.24 \mathrm{~g} \mathrm{~cm}^{-3}\right)$ and skeletal densities of UiO-66 as reported by ref. 37 .

et $a .^{31}$ reports an in-depth description on the role of monocarboxylic organic acids such as formic acid in the formation of defects in UiO-66, which results in increased BET surface areas compared to non-modulated (defect-free) UiO-66. The defects in crystals suggest the presence of open metal sites which can enhance the binding affinity of gas molecules at low gas pressures and may result in enhanced gas uptake than would be expected, especially within open metal centres contained in highly microporous environments such as found in MOFs. ${ }^{34,36}$

The trend in the total $\mathrm{H}_{2}$ uptake (wt\%) data shown in Fig. 3a is consistent with that observed for the surface area for the powdered and compacted UiO-66. The powder and compacted UiO-66 have relatively similar hydrogen uptake, which means that there was no compromise of total $\mathrm{H}_{2}$ uptake after compaction of UiO-66 powder at 665 MPa pressure. There were, however, slight differences in their adsorption isotherms as it can be seen that the excess $\mathrm{H}_{2}$ uptake in UiO-66 powder reaches a maximum at relatively low pressure (20-30 bar) after which there is a decrease up to 100 bar. This is the typical behaviour in physisorption-based gas uptake due to rapid adsorption onto the adsorbent surface at low surface coverage (high number of available binding sites) followed by a higher desorption to adsorption rate upon saturation of the surface excess (i.e. excess surface coverage $\approx 1){ }^{49}$ In the excess $\mathrm{H}_{2}$ isotherm for compacted UiO-66, the pressure at which maximum uptake is reached was much higher ( $>50 \mathrm{bar}$ ), and also there was no significant decrease up to 100 bar. The uptake of the $\mathrm{H}_{2}$ is reversible (Fig. S5, ESI $\dagger$ ) as the adsorption and desorption isotherms overlap. This is the expectation for physisorption based uptake and is also an indication of the robustness of our $\mathrm{H}_{2}$ sorption measurements.

Due to the compaction, it can be expected that access to binding sites/pores for $\mathrm{H}_{2}$ molecules would be more difficult due to the significant reduction in voids or macropores inbetween UiO-66 particles resulting in a reduced grain boundary between the UiO- 66 crystallites. As a result, the rate at which $\mathrm{H}_{2}$ molecules diffuse into the UiO-66 framework becomes reduced and higher pressures are required to reach maximum excess surface coverage and also the rate of desorption of $\mathrm{H}_{2}$ molecules within the pores becomes restricted by the close packing. The $\mathrm{H}_{2}$ adsorption at $298 \mathrm{~K}$ up to 100 bar in Fig. $3 \mathrm{~b}$ were found to be higher for the UiO-66 powder compared to compacted UiO-66. As expected, physical adsorption of $\mathrm{H}_{2}$ in porous materials becomes lowered as the temperature increases, and higher pressures are required to observe improved adsorption. ${ }^{49}$ The difference observed for powdered
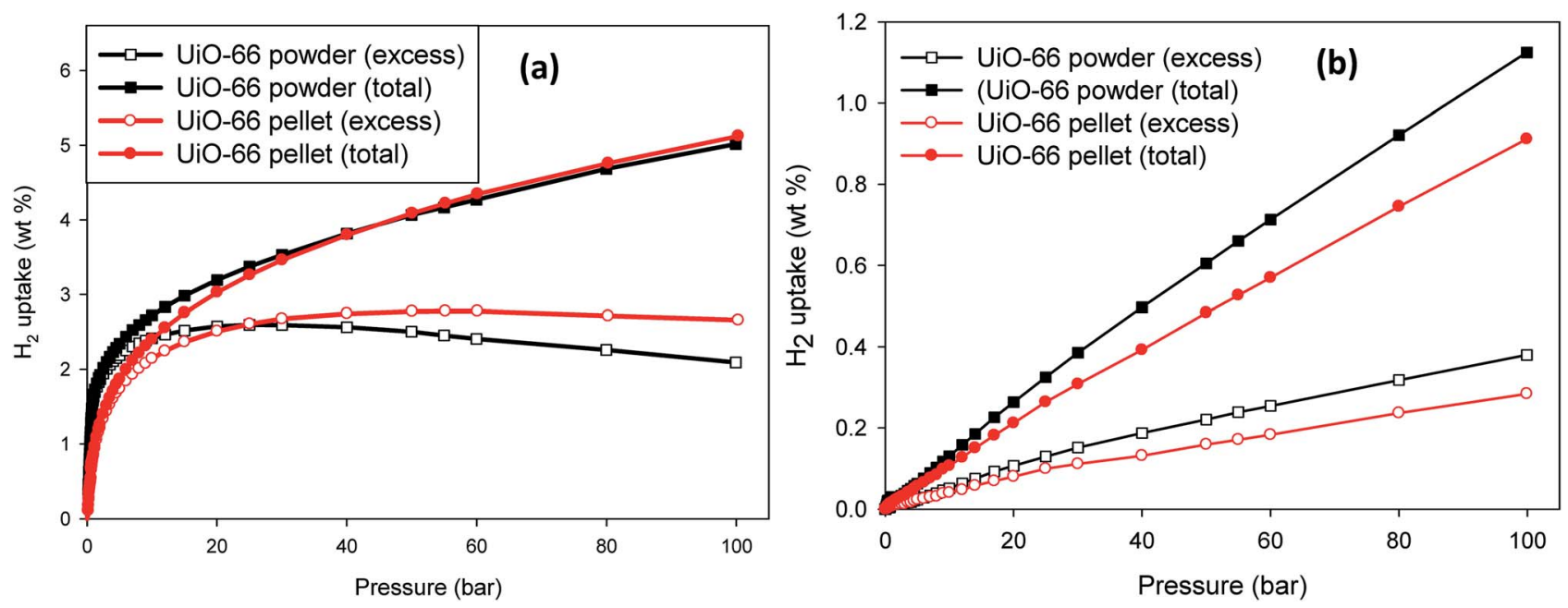

Fig. 3 Gravimetric $\mathrm{H}_{2}$ uptake (wt\%) for powder and compacted UiO-66 up to 100 bar measured at (a) $77 \mathrm{~K}$ and (b) $298 \mathrm{~K}$. The plots are for excess (open symbols) and total (closed symbols) $\mathrm{H}_{2}$ uptake. 
and compacted UiO-66 can be resulting from kinetic effects as the diffusion of $\mathrm{H}_{2}$ in compacted UiO-66 would be slower compared to UiO-66 powder and because of the significantly reduced $\mathrm{H}_{2}$ adsorption at $298 \mathrm{~K}$ compared to $77 \mathrm{~K}$, the excess $\mathrm{H}_{2}$ adsorption in compacted UiO-66 would only match that of powdered UiO-66 at pressures higher than 100 bar. The respective uptake values given in Table 1, comparing UiO-66 powder and UiO-66 pellet, show that at least $90 \%$ of the UiO66 textural properties are retained upon compaction at $665 \mathrm{MPa}$ applied pressure; the major difference is in their packing and skeletal densities, which influence the calculation of the total volumetric $\mathrm{H}_{2}$ capacity as given in eqn (3) and (4). As expected the packing density increased after compaction, however, it was interesting that the skeletal density also increased. The UiO-66 prepared in this study was a polycrystalline powder made up of different crystallite sizes (Fig. S1, ESI $\dagger$ ). The compaction of UiO-66 powder at sufficiently high pressure would thus result in the reduction of the grain boundary between the crystallites, reducing its volume in the densified state. This may result in some micropores to be inaccessible under non-equilibrium gas uptake measurements such as those used for helium pycnometry and result in higher skeletal density results.

For the purpose of this study, the volumetric $\mathrm{H}_{2}$ capacity was calculated using two methods. Fig. 4a and b shows data obtained using eqn (4) taking into account the recommendations made by Parilla et $a l .{ }^{38}$ for calculations based on gravimetric measurements of $\mathrm{H}_{2}$ uptake at high pressure. In Fig. 4a, the volumetric $\mathrm{H}_{2}$ capacity (at $77 \mathrm{~K}$ ) for compacted UiO-66 exceeds that of powdered UiO-66 from $25-100$ bar by up to $~ 26 \%$. Given that both the textural properties and the total gravimetric $\mathrm{H}_{2}$ uptake up to 100 bar were not compromised after compaction, the significant difference in volumetric $\mathrm{H}_{2}$ capacity can therefore be attributed to the improvement of the UiO-66 density after compaction. Indeed previous studies ${ }^{\mathbf{1 3 , 1 5 , 1 6}}$ have largely reported on the improvement of volumetric $\mathrm{H}_{2}$ capacity of MOFs due to compaction but there have been seldom reports where the MOF gravimetric $\mathrm{H}_{2}$ uptake is also not compromised with compaction. Furthermore, the ratio of the volume of $\mathrm{H}_{2}$ adsorbed to the volume of $\mathrm{H}_{2}$ in the gaseous/bulk phase
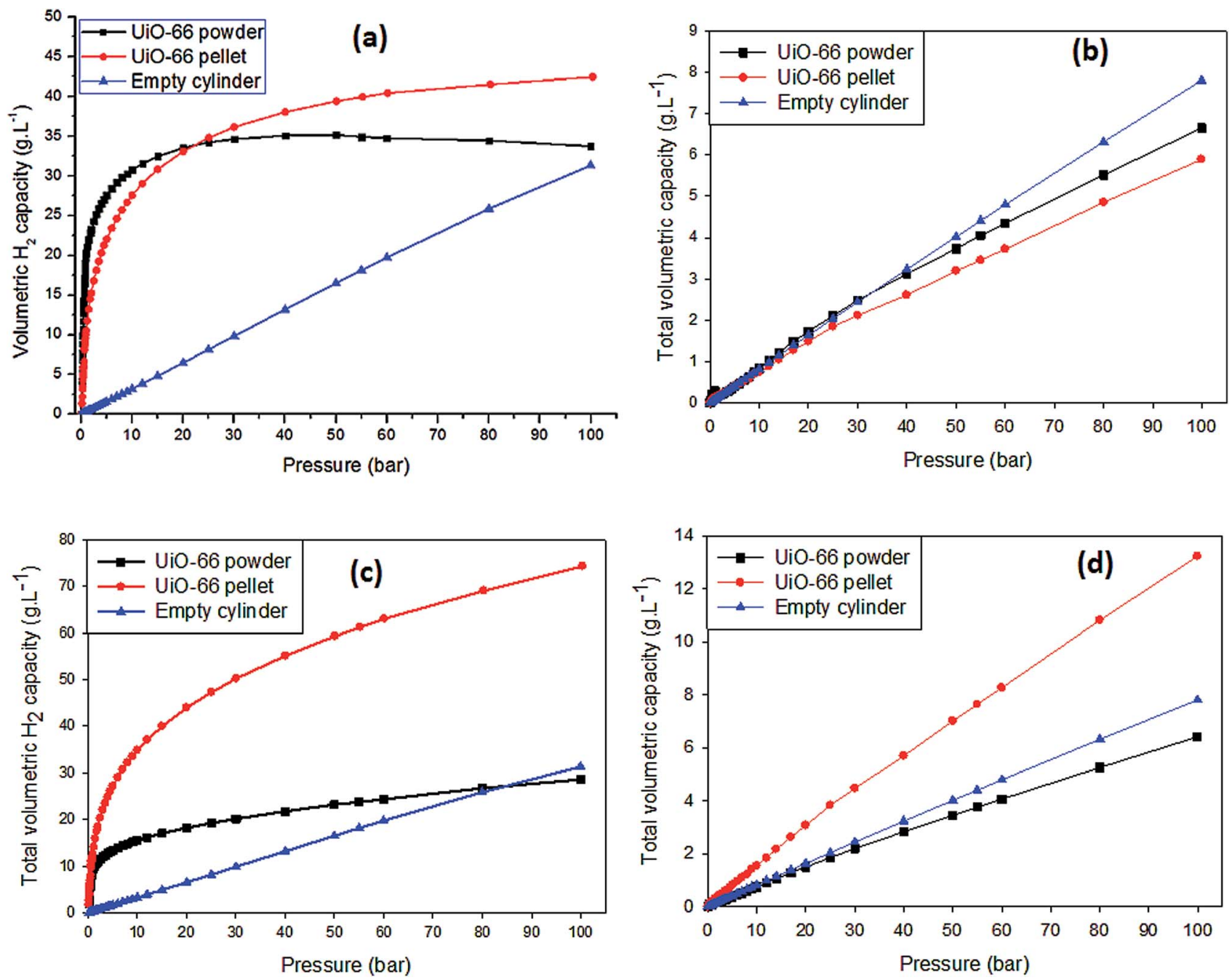

Fig. 4 Volumetric $\mathrm{H}_{2}$ isotherms for powdered and compacted UiO-66 up to 100 bar: (a and b) volumetric $\mathrm{H}_{2}$ capacity/density ( $\mathrm{L} \mathrm{L}^{-1}$ ) at $77 \mathrm{~K}$ and $298 \mathrm{~K}$ obtained using eqn (4), and (c and d) volumetric $\mathrm{H}_{2}$ capacity/density at $77 \mathrm{~K}$ and $298 \mathrm{~K}$ obtained using eqn (3). 
$\left(V_{\text {ad }} / V_{\text {bulk }}\right)$ can serve as an indication of the efficiency of $\mathrm{H}_{2}$ storage in the MOF compared to that of an empty container/ cylinder. Under the specified isotherm conditions $(T=77 \mathrm{~K}$, $0<P<100$ bar), the $\mathrm{H}_{2}$ density $\left(\mathrm{g} \mathrm{L}^{-1}\right)$ increases linearly with pressure and $V_{\text {ad }} / V_{\text {bulk }} \approx 1$ as calculated using the ideal gas law, i.e., no adsorption would be expected in an empty container. In the presence of UiO-66, as shown in Fig. S6 (ESI $\dagger$ ), the $V_{\text {ad }} / V_{\text {bulk }}$ ratio rapidly increases at pressures below 5 bar peaking at $80 \mathrm{~cm}^{3} \mathrm{~cm}^{-3}$ and $40 \mathrm{~cm}^{3} \mathrm{~cm}^{-3}$ for powdered and compacted UiO-66, respectively. This means that at pressures below 5 bar, UiO-66 stores at least 40 times more $\mathrm{H}_{2}$ by volume compared to the amount stored in an empty container/cylinder under the same conditions. As the pressure increased from $\sim 5$ bar up to 100 bar, the $V_{\text {ad }} / V_{\text {bulk }}$ ratio decreases sharply initially and then steadily towards $V_{\text {ad }} / V_{\text {bulk }} \approx 1$. The rapid increase in adsorbed $\mathrm{H}_{2}$ at low pressure can be attributed to the readily available adsorption sites (such as pores and pore walls). As these spaces/ sites become filled with mono- and/or multilayers of $\mathrm{H}_{2}$ molecules, the uptake of more $\mathrm{H}_{2}$ becomes restricted and may lead to an equilibrium state of adsorption being reached (i.e., saturation). Interestingly, from $\sim 30$ to $100 \mathrm{bar}, V_{\mathrm{ad}} / V_{\text {bulk }}$ for compacted UiO-66 is greater than that of the powdered UiO-66, showing more uptake of $\mathrm{H}_{2}$ at elevated pressures. This correlates with the excess adsorption isotherm obtained for compacted UiO-66 in relation to the UiO-66 powder, i.e., the densified sample takes up more excess $\mathrm{H}_{2}$. Clearly, the significant increase in the UiO-66 density after compaction at $665 \mathrm{MPa}$ translates to a rise in the calculated total volumetric $\mathrm{H}_{2}$ capacity. Similar to the gravimetric $\mathrm{H}_{2}$ uptake, the volumetric capacities were also found to be significantly lower at $298 \mathrm{~K}$ compared to $77 \mathrm{~K}$, and the UiO-66 powder had slightly higher uptake capacity than compacted UiO-66. This observation suggests that the adsorption onto compacted UiO-66 is significantly affected by kinetic effects under non-equilibrium $\mathrm{H}_{2}$ uptake conditions. Therefore, given that the surface area and pore volumes are effectively retained after compaction, it can be expected that at higher $\mathrm{H}_{2}$ adsorption pressures (greater than 100 bar), the room temperature volumetric hydrogen uptake capacity of compacted UiO-66 would exceed that of UiO-66 powder in a manner similar to that observed at $77 \mathrm{~K}$.

We also report in Table 1 and Fig. 4c, d the total volumetric $\mathrm{H}_{2}$ capacity calculated using the packing density of powdered and compacted UiO-66, which is currently the most commonly used method of calculating the total volumetric capacity. ${ }^{13,16,50-53}$ The results show that there is a remarkable increase in total volumetric $\mathrm{H}_{2}$ capacity from 29 to $74 \mathrm{~g} \mathrm{~L}^{-1}$ (6 to $13 \mathrm{~g} \mathrm{~L}^{-1}$ at $298 \mathrm{~K}$ ) due to the improved packing density of UiO-66 after compaction at $665 \mathrm{MPa}$ as calculated using eqn (3). The results however, do show a significant improvement of the total volumetric capacity due to compaction regardless of the mathematical model for conversion of gravimetric data into volumetric values.

We also take note of the results obtained at $77 \mathrm{~K}$ and $25 \mathrm{bar}$ (Table S2, ESI $\dagger$ ) based on a recent study by Balderas-Xicohténcatl et. al. ${ }^{55}$ showing that the volumetric $\mathrm{H}_{2}$ capacity in MOFs follows a linear relationship with the MOF's volumetric surface area $\left(\mathrm{m}^{2} \mathrm{~mL}^{-1}\right)$, similar to Chahine's rule. In our results, the compaction of UiO-66 powder increased the packing density from 0.57 to $1.45 \mathrm{~g} \mathrm{~mL}^{-1}$ and thus increasing the volumetric surface area from 990 to $2475 \mathrm{~m}^{2} \mathrm{~mL}^{-1}$. We see that multiplying the volumetric surface area by the slope $1.9 \times 10^{-2} \mathrm{~m}^{2} \mathrm{~mL}^{-1}$ (derived from calculations made by Balderas-Xicohténcatl et. $a l .{ }^{55}$ ) we obtain a calculated theoretical total volumetric capacity of 18 and $47 \mathrm{mg} \mathrm{mL} \mathrm{mL}^{-1}\left(\mathrm{~g} \mathrm{~L}^{-1}\right)$ for powder and compacted UiO-66, respectively. It is noteworthy that such a calculation yields virtually identical total volumetric capacities at $77 \mathrm{~K}$ and 25 bar, as calculated in our work described above using the packing density in eqn (3), for both powder and compacted UiO-66. The calculations and derivations made by BalderasXicohténcatl and co-workers were based on many different types of MOFs and also took into consideration the effect of compacting MOFs to increase packing densities. The strong agreement between our results to their estimations serves to validate our data and calculations and moreover, more generally, a strong indicator of the significant influence of packing density on volumetric $\mathrm{H}_{2}$ capacity in MOF powders and other related porous materials.

\section{Conclusion}

The aim of the study was an attempt at improving the total volumetric $\mathrm{H}_{2}$ capacity of UiO-66 without significantly reducing the gravimetric $\mathrm{H}_{2}$ uptake. Compaction of UiO-66 powder at 2, 4, 6, 8, and 10 metric tonnes (150, 290, 440, 590, and $665 \mathrm{MPa})$ did not lead to structural collapse of the UiO-66 crystal lattice. The compaction of MOFs at pressures as high as $665 \mathrm{MPa}$ ( 97 000 psi), without framework collapse, is unprecedented according to our knowledge as most previous studies have reported lower applied compaction pressures. ${ }^{13-23}$ The prepared UiO-66 had a surface area and total pore volume of $\sim 1700 \mathrm{~m}^{2}$ $\mathrm{g}^{-1}$ and $1.0 \mathrm{~cm}^{3} \mathrm{~g}^{-1}$, respectively. Furthermore, the surface area and micropore volume were retained to within at least $95 \%$ after compaction at $665 \mathrm{MPa}$. This non-changing porosity was translated in the total $\mathrm{H}_{2}$ uptake (at $77 \mathrm{~K}$ ) with powdered and compacted UiO-66 having 5.0 and $5.1 \mathrm{wt} \%$, respectively, at 100 bar. Given that the measurement techniques for surface area and $\mathrm{H}_{2}$ uptake were independent of each other, the results show an unambiguous outcome that clearly demonstrates the retention of textural and adsorption properties for UiO-66 upon compaction at $\sim 700 \mathrm{MPa}$. The compaction also predictably improved the UiO-66 density, with the skeletal and packing densities increasing from 1.65 to $1.78 \mathrm{~g} \mathrm{~cm}^{-3}$ and 0.57 to $1.45 \mathrm{~g} \mathrm{~cm}^{-3}$, respectively. The total volumetric $\mathrm{H}_{2}$ capacity was higher for the compacted UiO-66 than powdered UiO-66, regardless of the model/method of calculation utilized to convert gravimetric data into volumetric values. Using the model developed by Ahmed et al. ${ }^{37}$ we obtained a volumetric $\mathrm{H}_{2}$ capacity of $43 \mathrm{~g} \mathrm{~L}^{-1}$ (100 bar, $77 \mathrm{~K}$ ) and $6 \mathrm{~g} \mathrm{~L}^{-1}$ (100 bar, $298 \mathrm{~K}$ ) for compacted UiO-66 compared to $35 \mathrm{~g} \mathrm{~L}^{-1}$ (100 bar, $77 \mathrm{~K}$ ) and $6 \mathrm{~g} \mathrm{~L}^{-1}$ (100 bar, $298 \mathrm{~K}$ ) for powdered UiO-66. Using the packing densities, which is the most commonly reported method for calculations, the volumetric $\mathrm{H}_{2}$ capacity at 100 bar was calculated to be $74 \mathrm{~g} \mathrm{~L}^{-1}\left(13 \mathrm{~g} \mathrm{~L}^{-1}\right.$ at $\left.298 \mathrm{~K}\right)$ and $29 \mathrm{~g} \mathrm{~L}^{-1}\left(6 \mathrm{~g} \mathrm{~L}^{-1}\right.$ at $298 \mathrm{~K}$ ) for compacted and powdered UiO-66, respectively. Even 
though the calculated values of total volumetric $\mathrm{H}_{2}$ capacity differ depending on the model used, the results however, clearly show an improvement in volumetric capacity upon compacting UiO-66. The results obtained in this study show that the fabrication of MOFs using techniques such as compaction can serve as a basis for developing MOF-based materials that can satisfy both gravimetric and volumetric US DOE targets for a single material.

\section{Conflicts of interest}

There are no conflicts of interest to declare.

\section{Acknowledgements}

The authors would like to acknowledge financial support from the Royal Society - DFID Africa Capacity Building Initiative Programme (Grant No. AQ150029), and the South African Department of Science and Technology (DST) towards HySA Infrastructure (Project No. EIMH01X).

\section{References}

1 M. P. Suh, H. J. Park, T. K. Prasad and D. Lim, Chem. Rev., 2017, 112, 782-835.

2 O. K. Farha, A. O. Yazaydin, I. Eryazici, C. D. Malliakas, B. G. Hauer, M. G. Kanatzidis, S. T. Nguyen, R. Q. Snurr and J. T. Hupp, Nat. Chem., 2010, 2, 944.

3 J. Yang, A. Sudik, C. Wolverton and D. J. Siegel, Chem. Soc. Rev., 2010, 39(2), 656-675.

4 A. J. Howarth, A. W. Peters, N. A. Vermeulen, T. C. Wang, J. T. Hupp and O. K. Farha, Chem. Mater., 2017, 19, 26-39.

5 J. Klinowski, F. A. Almeida Paz, P. Silva and J. Rocha, Dalton Trans., 2011, 40(2), 321-330.

6 J. Ren, S. Segakweng, H. W. Langmi, N. M. Musyoka, B. C. North, M. Mathe and D. Bessarabov, Int. J. Mater. Res., 2014, 105(5), 516-519.

7 L. Paseta, G. Potier, S. Sorribas and J. Coronas, ACS Sustainable Chem. Eng., 2016, 4(7), 3780-3785.

8 W. P. R. Deleu, I. Stassen, D. Jonckheere, R. Ameloot and D. E. De Vos, J. Mater. Chem. A, 2016, 4(24), 9519-9525.

9 X. Dyosiba, J. Ren, N. M. Musyoka, H. W. Langmi, M. Mathe and M. S. Onyango, Sustainable Mater. Technol., 2016, 10, 10-13.

10 J. Ren, X. Dyosiba, N. M. Musyoka, H. W. Langmi, B. C. North, M. Mathe and M. S. Onyango, Int. J. Hydrogen Energy, 2016, 41, 1841-1846.

11 Technical System Targets: Onboard Hydrogen Storage for Light-Duty Fuel Cell Vehicles, cited on 29 June 2018 from: https://www.energy.gov/sites/prod/files/2017/05/f34/fcto_ myrdd_table_onboard_h2_storage_systems_doe_targets_ ldv_1.pdf.

12 J. Goldsmith, A. G. Wong-Foy, M. J. Cafarella and D. J. Siegel, Chem. Mater., 2013, 25(16), 3373-3382.

13 J. J. Purewal, D. Liu, J. Yang, A. Sudik, D. J. Siegel, S. Maurer and U. Müller, Int. J. Hydrogen Energy, 2012, 37(3), 2723-2727.

14 R. Zacharia, D. Cossement, L. Lafi and R. Chahine, J. Mater. Chem., 2010, 20(11), 2145-2151.
15 G. Blanita, I. Coldea, I. Misan and D. Lupu, Int. J. Hydrogen Energy, 2014, 39(30), 17040-17046.

16 O. Ardelean, G. Blanita, G. Borodi, M. D. Lazar, I. Misan, I. Coldea and D. Lupu, Int. J. Hydrogen Energy, 2013, 38(17), 7046-7055.

17 G. W. Peterson, J. B. Decoste, T. G. Glover, Y. Huang, H. Jasuja and K. S. Walton, Microporous Mesoporous Mater., 2013, 179, 48-53.

18 S. A. Moggach, T. D. Bennett and A. K. Cheetham, Angew. Chem., Int. Ed., 2009, 48(38), 7087-7089.

19 D. Bazer-Bachi, L. Assié, V. Lecocq, B. Harbuzaru and V. Falk, Powder Technol., 2014, 255, 52-59.

20 F. X. Coudert, Chem. Mater., 2015, 27(6), 1905-1916.

21 M. C. Raj, S. Senthilkumar, R. S. Somani and H. C. Bajaj, Int. J. Environ. Stud., 2016, 73(3), 357-368.

22 K. Chapman, G. Halder and P. Chupas, J. Am. Chem. Soc., 2009, 131, 17546-17547.

23 N. Chanut, A. D. Wiessum, U.-H. Lee, Y. K. Hwang, F. Ragon, H. Chvreau, S. Bourrelly, B. Kuchta, J.-S. Chang, C. Serre and P. L. Llewellyn, Eur. J. Inorg. Chem., 2016, 2016(27), 4416-4423.

24 J. Ren, N. M. Musyoka, H. W. Langmi, T. Segakweng, B. C. North, M. Mathe and K. Xiangdong, Int. J. Hydrogen Energy, 2014, 39(23), 12018-12023.

25 M. J. Katz, Z. J. Brown, Y. J. Colón, P. W. Siu, K. A. Scheidt, R. Q. Snurr, J. T. Hupp and O. K. Farha, Chem. Commun., 2013, 49(82), 9449.

26 Q. Yang, A. D. Wiersum, P. L. Llewellyn, V. Guillerm, C. Serre and G. Maurin, Chem. Commun., 2011, 47(34), 9603.

27 J. Ren, H. W. Langmi, B. C. North, M. Mathe and D. Bessarabov, Int. J. Hydrogen Energy, 2014, 39(2), 890-895.

28 A. Schaate, P. Roy, A. Godt, J. Lippke, F. Waltz, M. Wiebcke and P. Behrens, Chem.-Eur. J., 2011, 17(24), 6643-6651.

29 S. Øien, D. Wragg, H. Reinsch, S. Svelle, S. Bordiga, C. Lamberti and K. P. Lillerud, Cryst. Growth Des., 2014, 14(11), 5370-5372.

30 L. Valenzano, B. Civalleri, S. Chavan, S. Bordiga, M. H. Nilsen, S. Jakobsen, K. P. Lillerud and C. Lamberti, Chem. Mater., 2011, 23(7), 1700-1718.

31 G. C. Shearer, S. Chavan, S. Bordiga, S. Svelle, U. Olsbye and K. P. Lillerud, Chem. Mater., 2016, 28(11), 3749-3761.

32 H. Wu, Y. S. Chua, V. Krungleviciute, M. Tyagi, P. Chen, T. Yildirim and W. Zhou, J. Am. Chem. Soc., 2013, 135, 10525-10532.

33 G. C. Shearer, S. Chavan, J. Ethiraj, J. G. Vitillo, S. Svelle, U. Olsbye, C. Lamberti, S. Bordiga and K. P. Lillerud, Chem. Mater., 2014, 26(14), 4068-4071.

34 T. K. A. Hoang and D. M. Antonelli, Adv. Mater., 2009, 21(18), 1787-1800.

35 C. Chung, J. Ihm and H. Lee, J. Korean Phys. Soc., 2015, 66(11), 1649-1655.

36 M. R. Andalibi, A. Qajar and H. C. Foley, J. Phys. Chem. C, 2015, 119(37), 21314-21322.

37 A. Ahmed, Y. Liu, J. Purewal, L. D. Tran, A. G. Wong-Foy, M. Veenstra, A. J. Matzger and D. J. Siegel, Energy Environ. Sci., 2017, 10(11), 2459-2471.

38 P. A. Parilla, K. Gross, K. Hurst and T. Gennett, Appl. Phys. A: Mater. Sci. Process., 2016, 122(3), 1-18. 
39 Y. Zhao, Q. Zhang, Y. Li, R. Zhang and G. Lu, ACS Appl. Mater. Interfaces, 2017, 9, 15079-15085.

40 M. Kandiah, M. H. Nilsen, S. Usseglio, S. Jakobsen, U. Olsbye, M. Tilset, C. Larabi, E. A. Quadrelli, F. Bonino and K. P. Lillerud, Chem. Mater., 2010, 22(10), 6632-6640.

41 J. H. Cavka, S. Jakobsen, U. Olsbye, N. Guillou, C. Lamberti, S. Bordiga and K. P. Lillerud, J. Am. Chem. Soc., 2008, 130(42), 13850-13851.

42 S. J. Garibay and S. M. Cohen, Chem. Commun., 2010, 46(41), 7700-7702.

43 S. Chavan, J. G. Vitillo, O. Gianolio, O. Zavorotynska, B. Civalleri, S. Jakobsen, M. H. Nilsen, L. Valenzano, C. Lamberti, K. P. Lillerud and S. Bordiga, Phys. Chem. Chem. Phys., 2012, 14(5), 1614-1626.

$44 \mathrm{H}$. Wu, T. Yildirim and W. Zhou, J. Phys. Chem. Lett., 2013, 4(6), 925-930.

45 A. U. Ortiz, A. Boutin, A. H. Fuchs and F. Coudert, Phys. Lett., 2012, 109, 195502.
46 G. W. Peterson, S.-Y. Moon, G. W. Wagner, M. G. Hall, J. B. DeCoste, J. T. Hupp and O. K. Farha, Inorg. Chem., 2015, 54, 9684-9686.

47 C. H. Lau, R. Babarao and M. R. Hill, Chem. Commun., 2013, 49, 3634-3636.

48 K. Wang, C. Li, Y. Liang, T. Han, H. Huang, Q. Yang, D. Liu and C. Zhong, Chem. Eng. J., 2016, 289, 486-493.

49 K. M. Thomas, Catal. Today, 2007, 120(3-4), 389-398.

50 H. Furukawa, M. A. Miller and O. M. Yaghi, J. Mater. Chem., 2007, 17(30), 3197-3204.

51 A. Dailly and E. Poirier, Energy Environ. Sci., 2011, 4(9), 35273534.

52 L. Zhou, Renewable Sustainable Energy Rev., 2005, 9(4), 395408.

53 G. Ye, H. Xin, Z. Bao-lin, M. Bao-guo and Z. Hong-bo, Powder Technol., 2008, 187(1), 88-93.

54 Thermophysical properties of fluid systems, Cited on 15 February 2018 from: http://www.nist.gov.

55 R. Balderas-Xicohténcatl, M. Schlichtenmayer and M. Hirscher, Energy Technol., 2018, 6, 578-582. 